\section{Ethephon Promotes Germination of Echinacea angustifolia and E. pallida in Darkness}

\author{
Luping Qu, Xiping Wang, ${ }^{1}$ Jinghua Yang, Eatherley Hood, and \\ Richard Scalzo \\ Gaia Herbs, Inc., 108 Island Ford Road, Brevard, NC 28712
}

Additional index words. Echinacea purpurea, seed dormancy, cold stratification

\begin{abstract}
Seeds from five lots each of Echinacea angustifolia DC and E. pallida (Nutt.) Nutt. were germinated in a growth chamber in light $\left(40 \mu \mathrm{mol} \cdot \mathrm{m}^{-2} \cdot \mathrm{s}^{-1}\right)$ or darkness at $25^{\circ} \mathrm{C}$ for 16 to 20 days after soaking in $1 \mathrm{~mm}$ ethephon or water for 10 minutes or moist stratification at 4-6 ${ }^{\circ} \mathrm{C}$ for 2 weeks. Either light or ethephon promoted seed germination of $E$. angustifolia and $E$. pallida compared with darkness in nine of ten lots. Ethephon in the dark had similar or greater germination percentages than water with light. Ethephon with light improved germination in three of ten lots compared with ethephon in the dark. The effect of cold, moist stratification compared with darkness varied by seed lot. Five lots of $E$. purpurea (L.) Moench were tested, however, no treatment differences were measured. The finding that ethethon promoted $E$. angustifolia and $E$. pallida seed germination in darkness could be useful in the cultivation of these two species. Chemical name used: 2-chloroethylphosphonic acid (ethephon).
\end{abstract}

Echinacea species are among the most important medicinal plants native to North America. Echinacea has long been used by $\mathrm{Na}$ tive Americans to treat many conditions including venomous bites, rabies, cold, headaches, and stomach cramps (Kindscher, 1989; Foster 1991; $\mathrm{Li}, 1998)$. The nonselective immune-enhancing properties of Echinacea extract in humans have promoted the use and demand of Echinacea products recently and consequently its field production. Of the nine Echinacea species, E. angustifolia (root) and E. purpurea (root and aerial parts) are used most extensively in the medicinal herbal dietary supplement industry, followed by E. pallida (root) (Li, 1998).

Low and erratic germination of Echinacea seeds has impaired field establishment of Echinacea, resulted in reduced yield, and diminished grower profitability. Low seed germination in various species may be due to dormancy mechanism(s) residing in the embryo, the seedcoat, or integuments (Bradbeer, 1988). Seed treatments that overcome dormancy include cold stratification, dry storage, elevated temperatures, light, leaching, scarification, and exposure to chemicals (Bradbeer, 1988). Methods used to break Echinacea seed dormancy have included cold stratification (Bratcher et al., 1993; Parmenter, 1996; Wartidiningsih et al., 1994), treatment with potassium hydroxide (Gao et al., 1998), treatment with gibberellic acid (Pill and Haynes, 1996), or mechanical scarification (Feghahati and Reese, 1994; Sorenen and Holden, 1974). Seed lot and maturity stage also influenced germination (Wartidiningsih and Geneve, 1994).

Several workers have shown ethephon

Received for publication 14 Feb. 2003. Accepted for publication 12 Aug. 2003. This publication is made possible by grant number 1R44AT771-01 from the National Center for Complementary and Alternative Medicine.

${ }^{1}$ To whom reprint requests should be addressed; e-mailx0w@gaiaherbs.com. (2-chloroethylphosphonic acid) that releases ethylene to be effective in breaking Echinacea seed dormancy. Feghahati and Reese (1994) achieved $>90 \%$ germination of $E$. angustifolia seeds by combining ethephon, chilling, and light exposure. Sari et al. (2001) increased germination by treating E. angustifolia and E. pallida seeds with ethephon in light without chilling. Light was considered a necessary factor in enhancing $E$. angustifolia seed germination (Feghahati and Reese, 1994). In E. purpurea, the effect of light on seed germination has varied, either promoting seed germination (Smith-Jochum and Albrecht, 1987) or having no effect (Wartidiningsih and Geneve, 1994). The effect of ethephon on Echinacea seed germination in darkness has not been reported. Since risks of seed desiccation and loss due to wind or bird predation exist when seeds are exposed to light during germination, methods that can reduce light requirements during seed germination would be very helpful in Echinacea field establishment.

This research was conducted to evaluate the effectiveness of ethephon on seed germination of the three Echinacea species (E. angustifolia, E. pallida, and E. purpurea) in darkness.

\section{Materials and Methods}

The germination tests were conducted in February and March 2002. Seeds of E. angustifolia, E. pallida, and E. purpurea were received from seven seed companies (Ion Exchange, Harpers Ferry, Iowa; Johnny's Selected Seeds, Albion, Maine; Prairie Nursery, Westfield, Wis.; Prairie Moon Nursery, Winona, Minn.; Richters, Goodwood, Ont., Canada; Stock Seed Farms, Murdock, Neb.; Wind River Seed, Manderson, Wyo.) and stored at room temperatures for $\approx 1$ month before the experiments began. The age and storage conditions (obtained through communications with lot are listed in Table 1. representatives of the companies) of each seed
Selected combinations of light, ethephon and moist chilling were tested on five lots of each species. Treatments were as follows.

1) Constant light + ethephon. Seeds were soaked in 50-mL beakers with $10 \mathrm{~mL}$ of $1 \mathrm{~mm}$ ethephon (Florel, Lawn and Garden products, Inc. Fresno, Calif.) for $10 \mathrm{~min}$. The beakers were shaken gently on a rotary shaker at 100 $\mathrm{rpm}$. After soaking, seeds were blotted dry on paper towels and placed in the germination boxes that were sealed with parafilm.

2) Constant darkness + ethephon. Seeds were treated the same as in treatment 1 , but the germination boxes were wrapped with aluminum foil.

3) Light + water. This treatment was identical to treatment 1 , except that seeds were soaked in deionized (DI) water.

4) Darkness + water. This treatment was identical to treatment 3, except that the germination boxes were wrapped with aluminum foil.

5) Cold stratification. Seeds were placed in germination boxes on two layers of filter paper saturated with DI water. The boxes were sealed with parafilm and placed in a refrigerator (4 to $6{ }^{\circ} \mathrm{C}$ ) for 2 weeks and then transferred to the growth chamber under constant light. For treatments in darkness, boxes were placed on the lower shelves in the growth chamber to reduce possible light interference effects by the wrapped boxes on the light treatments.

Each treatment contained 25 seeds placed in transparent plastic germination boxes (11 $\times 11 \times 3.5 \mathrm{~cm})$ on two layers of Whatman \#1 filter paper saturated with the appropriate treatment solutions, and was replicated four times. Germination tests were conducted in a growth chamber (Precision model 818) at constant 25 ${ }^{\circ} \mathrm{C}$. Cool white fluorescent lamps mounted on the chamber door provided photosynthetically active radiation at $40 \mu \mathrm{mol} \cdot \mathrm{m}^{-2} \cdot \mathrm{s}^{-1}$. Germination (radicals $>1 \mathrm{~mm}$ long) was recorded daily for the treatments in light and after $6 \mathrm{~d}$ for treatments in darkness and then at 3-d intervals. Germinated seeds were removed when counted, and seed germination was monitored for 16 to $20 \mathrm{~d}$.

Each experiment was a completely randomized design. Germination percentages were normalized by transformation (arc$\sin \sqrt{ } \%$ ) before being subjective to analysis of variance.

\section{Results and Discussion}

A significant interaction was measured between treatments and seed lots in E. angustifolia and E. pallida, but only seed lot was significant for E. purpurea (Table 2). For the darkness + water treatment, either light or ethephon promoted germination of E. angustifolia and E. pallida (except lot E-pal 1) seeds (Table 2). The promotive effect of light on seed germination was reduced greatly in ethephon-treated seeds. In darkness with ethephon, all the seeds germinated similarly or greater than in light and water. Although light with ethephon resulted in the greatest overall effectiveness in promoting seed germination, germination percentages in darkness with ethephon were equally as high as in light with ethephon for seeds from three 
Table 1. Seed information of Echinecea species before testing ${ }^{2}$.

\begin{tabular}{|c|c|c|c|c|}
\hline Species & $\begin{array}{l}\text { Seed } \\
\text { origin }\end{array}$ & $\begin{array}{l}\text { Harvest } \\
\text { year }\end{array}$ & $\begin{array}{l}\text { Storage conditions } \\
\text { before tests }\end{array}$ & $\begin{array}{l}\text { Germination (\%) } \\
\text { and test date }\end{array}$ \\
\hline E-ang 1 & Oregon & 2001 & Refrigerator $\left(4\right.$ to $\left.6^{\circ} \mathrm{C}\right)$ & 30 (Dec. 2001) \\
\hline E-ang 4 & South Dakota & 1998 & $\mathrm{AC}^{\mathrm{y}}$ with dehumidifier & 94 (Nov. 2001) \\
\hline E-ang 5 & Wyoming & 2000 & No temperature or humidity control & 66 (Apr. 2001) \\
\hline \multicolumn{5}{|c|}{ 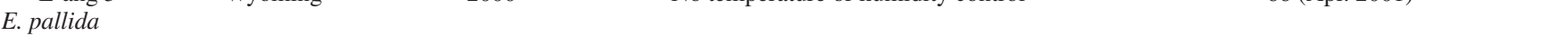 } \\
\hline E-pal 3 & Illinois & 2000 & Cool dry, 12 to $16^{\circ} \mathrm{C}$ & 84 (June 2001) \\
\hline E-pal 4 & Iowa & 2000 & Summer 12 to $16^{\circ} \mathrm{C}$; winter: natural condition & $30 ; 64 \%$ dormant (Nov. 2001) \\
\hline E-pal 5 & Nebraska & 2000 & No temperature or humidity control & $43 ; 49 \%$ dormant (Sept. 2001) \\
\hline \multicolumn{5}{|l|}{ E. purpurea } \\
\hline E-pur 1 & Oregon & 2000 & Refrigerator $\left(4\right.$ to $\left.6^{\circ} \mathrm{C}\right)$ & 65 (Jan. 2002) \\
\hline E-pur 2 & Colorado & 2000 & $\mathrm{Cool}\left(12\right.$ to $\left.16^{\circ} \mathrm{C}\right)$, dry & 94 (Dec. 2000) \\
\hline E-pur 3 & Colorado & 2000 & Summer 12 to $16^{\circ} \mathrm{C}$; winter: natural condition & 96 (July 2001) \\
\hline
\end{tabular}

${ }^{2}$ Information obtained through communications with seed company representatives;

${ }^{\mathrm{y}}$ Air conditioning.

lots of E. angustifolia (E-ang 3, E-ang 4, E-ang 5 ) and four lots of E pallida (E-pal 1, E-pal 2, E-pal 4, E-pal 5). Across the seed lots treated with water, germination on average in darkness was reduced by $25 \%$ for E. angustifolia and $32 \%$ for E. pallida compared to that in light. In the ethephon treatments, overall reduction of germination in darkness compared to that in light was $<3 \%$ for E. angustifolia and $\approx 7 \%$ for E. pallida. Cold stratification relative to the treatment of water with darkness promoted seed germination of one lot of E. angustifolia (E-ang 5) and E. pallida (E-pal2), respectively. No treatment effects were measured for $E$. purpurea.

Our results that ethephon enhanced seed germination in two of the five E. angustifolia seed lots, three of the five E. pallida seed lots in light, and four of five in E. pallida and five of five in E. augustifolia in darkness provide further support that ethephon is effective in breaking seed dormancy of these two species (Feghahati and Reese, 1994; Sari et al. 2001). Ethephon also shortened germination time. In light with ethephon, $\approx 90 \%$ of the final germination of E. angustifolia and E. pallida seeds occurred in $4 \mathrm{~d}$. It took 8 to $12 \mathrm{~d}$ to reach similar percentages without ethephon. For all three species treated with ethephon in darkness, $\approx 90 \%$ of the final germination occurred when the first count was made (day 6), and $\approx 80 \%$ in the treatment without ethephon. This indicates that short exposure $(<1 \mathrm{~min})$ to light during germination evaluation had little if any effect on final germination. Our recent experiments using E. angustifolia seeds harvested in 2002 showed that short time exposure to light had no effects on germination in 8 to 15 duration darkness tests ( $\mathrm{Qu}$, unpublished data).

Promotive effects of light on seed germination of some species have long been noticed (Evenari, 1965; Bradbee, 1988). The promotive light effect on Echinacea seed germination (Table 2) was consistent with previous findings. Synergistic effects of light and chilling (Baskin et al., 1992), light and ethephon (Sari et al., 2001), and light, ethephon, and chilling (Feghahati and Reese, 1994) were reported on E. angustifolia seed germination. There have been no reports of ethephon effects on Echinacea seed germination in darkness. Our results demonstrated that ethephon generally promoted germination of E. angustifolia and E. pallida seeds in both darkness and light. For most seed lots, similar germination was achieved in light or darkness when the seeds were treated with ethephon (Table 2). This finding is important in that it suggests that most seeds of these two species treated with ethephon could be covered with growth medium after sowing without causing reduced germination. This could reduce the risk of seed desiccation and seed loss due to wind and bird predation. Weak seedlings were observed from uncovered seeds because the radical penetrated the soil slowly, increasing the likelihood that seedlings could desiccate and weaken $(\mathrm{Qu}$, unpublished data).

The germination differences of E. augustifolia and E. palllida seeds in darkness or light or after ethephon treatment may suggest that the seed dormancy in Echinacea is complex. Seeds in full dormancy could not germinate either in light or darkness, but, once dormancy was partially released, germination was improved in light but not in darkness. With further release, germination was unaffected by light or darkness, such as for E. pallida E-pal 1. Dormancy can be broken very effectively by ethephon, although some seed lot variation exists. The high germination of E. purpurea seeds under any of the treatments may indicate that they

Table 2. Effects of treatments on seed germination of Echinacea species from different seed lots.

\begin{tabular}{|c|c|c|c|c|c|c|}
\hline \multirow{2}{*}{$\begin{array}{l}\text { Treatment } \\
\text { E. angustifolia }\end{array}$} & & \multicolumn{5}{|c|}{ Seed lot } \\
\hline & & E-ang 1 & E-ang-2 & E-ang 3 & E-ang 4 & E-ang 5 \\
\hline Light-ethephon & & $86 a^{2}$ & $92 \mathrm{a}$ & $75 \mathrm{a}$ & $85 \mathrm{a}$ & $41 \mathrm{a}$ \\
\hline Dark-ethephon & & $69 \mathrm{~b}$ & $80 \mathrm{~b}$ & $80 \mathrm{a}$ & $84 \mathrm{a}$ & $55 \mathrm{a}$ \\
\hline Light-water & & $64 \mathrm{~b}$ & $62 \mathrm{c}$ & $80 \mathrm{a}$ & $85 \mathrm{a}$ & $48 \mathrm{a}$ \\
\hline Dark-water & & $35 \mathrm{c}$ & $32 \mathrm{~d}$ & $53 \mathrm{~b}$ & $70 \mathrm{~b}$ & $26 \mathrm{~b}$ \\
\hline Chilling light-water & & No test & $36 \mathrm{~d}$ & No test & $54 \mathrm{c}$ & $50 \mathrm{a}$ \\
\hline \multicolumn{7}{|l|}{ ANOV (two-way) } \\
\hline Treatment $(\mathrm{T})$ & $* * *$ & & & & & \\
\hline Seed lot $(\mathrm{S})$ & $* * *$ & & & & & \\
\hline $\mathrm{T} \times \mathrm{S}$ & $* *$ & & & & & \\
\hline E. pallida & & E-pal 1 & E-pal 2 & E-pal 3 & E-pal 4 & E-pal 5 \\
\hline Light-ethephon & & $92 \mathrm{a}$ & $91 \mathrm{a}$ & $54 \mathrm{a}$ & $88 \mathrm{a}$ & $90 \mathrm{a}$ \\
\hline Dark-ethephon & & $94 \mathrm{a}$ & $87 \mathrm{a}$ & $38 \mathrm{~b}$ & $72 \mathrm{a}$ & $89 \mathrm{a}$ \\
\hline Light-water & & $90 \mathrm{a}$ & $79 \mathrm{ab}$ & $36 \mathrm{~b}$ & $59 \mathrm{c}$ & $49 \mathrm{~b}$ \\
\hline Dark-water & & $86 \mathrm{a}$ & $34 \mathrm{c}$ & $3 \mathrm{c}$ & $7 \mathrm{~d}$ & $22 \mathrm{c}$ \\
\hline Chilling light-water & & $68 \mathrm{~b}$ & $66 \mathrm{~b}$ & $1 \mathrm{c}$ & No test & $35 \mathrm{bc}$ \\
\hline \multicolumn{7}{|l|}{ ANOV (two way) } \\
\hline Treatment $(\mathrm{T})$ & $* * *$ & & & & & \\
\hline Seed lot (S) & *** & & & & & \\
\hline $\mathrm{T} \times \mathrm{S}$ & $* * *$ & & & & & \\
\hline E. purpurea & & E-pur 1 & E-pur 2 & E-pur 3 & E-pur 4 & E-pur 5 \\
\hline \multicolumn{7}{|l|}{ ANOV (two-way) } \\
\hline Treatment $(\mathrm{T})$ & NS & & & & & \\
\hline Seed lot $(\mathrm{S})$ & $* * *$ & $67 \mathrm{~b}$ & $96 \mathrm{a}$ & $84 \mathrm{a}$ & $94 \mathrm{a}$ & $95 \mathrm{a}$ \\
\hline $\mathrm{T} \times \mathrm{S}$ & NS & & & & & \\
\hline
\end{tabular}

${ }^{2}$ Mean separation within columns or rows for each species by Duncan's multiple range test. ${ }^{y}$ Chilling light-water are not included in two way ANOV due to some seeds not tested. ${ }_{\mathrm{Ns}, * *, * * *}$ Nonsignificant or significant at $P<0.001$ or 0.0001 , respectively. 
had been fully released from dormancy during dry storage.

Seed age ranged from 1 to 5 years (Table 1) when we conducted the germination tests. There was no indication of a consistent effect of age differences on seed germination. In our tests, high germination existed in both younger and older seeds in light without ethephon. This may suggest that dormancy in these seeds is broken during seed storage. Seeds were stored at 4 to $16^{\circ} \mathrm{C}$ at the seed companies and at room temperature and relative humidity after we received them. Temperature, light, humidity, and the time required for dormancy release under dry storage should be investigated further. Parental genotypes, mother plant cultural environments, and seed maturity at harvest could play a role in the release of dormancy under dry storage conditions.

Low percentage germination after cold, moist stratification suggests that such a treatment may not promote germination of Echinacea seeds that have been fully or even partially released from dormancy (Table 2). We observed that chilled seeds had prolonged germination time and greater incidence of damping off (data not shown). The effects of moist-chilling of Echinacea seeds on germination have been varied. For instance, such treatments increased germination of E. angustifolia (Feghahati and Reese 1994; Parmenter et al., 1996) and
E. purpurea (Wartidiningsih et al., 1994). However, after $40 \mathrm{~d}$ of stratification at $2{ }^{\circ} \mathrm{C}$, Shalaby et al. (1997) found $0 \%$ to $1 \%$ germination of E. pallida and E. angustifolia seeds, and Parmenter et al. (1996) found chilling to have no effect on germination of E. purpurea seeds. Therefore, tests should be conducted before treating Echinacea seeds with cold, moist stratification since it may be ineffective in promoting germination.

The results of this investigation indicate that light should be provided to promote seed germination of E. angustifolia and E. pallida. For most seed lots of these two species, light may not be necessary when seeds have been treated with ethephon.

\section{Literature Cited}

Bradbeer, J.W. 1988. Seed and germination, p. 38-94. Chapman \& Hall, New York.

Bratcher, C.B., J.M. Dole, and J.C. Cole. 1993. Stratification improves germination of five native wildflower species. HortScience 28:899-901.

Evenari, M. 1965. Light and seed dormancy, p. 804-847. In: W. Ruhland (ed.). Encyclopedia of plant physiology. vol. XV/2. Springer, Berlin and Heidelberg.

Feghahati, S.M.J. and R.N. Reese. 1994. Ethylene-, light-, and prechill-enhanced germination of Echinacea angustifolia seeds. J. Amer. Soc. Hort. Sci. 119:853-858.

Foster, S. 1991. Echinacea: Nature's immune en- hancer. Healing Arts Press. Rochester, Vt.

Gao, Y.P., G.H. Zheng, and L.V. Gusta. 1998. Potassium Hydroxide improves seed germination and emergence in five native plant species. HortScience 33:274-276.

Kindscher, K. 1989. Ethnobotany of purple conflower (Echinacea angustifolia, Asteceae) and other Echinacea species. Econ. Bot. 43:498-507.

Li, T.S.C. 1998. Echinacea: Cultivation and medicinal value. HortTechnology 8:122-129.

Parmenter, G.A. 1996. Chilling requirement of commercial Echinacea seed. N.Z. J. Crop Hort. Sci. 24:109-114.

Pill, W.G. and J.G. Haynes. 1996. Gibberellic acid during priming of Echinaceapurpurea L. Moench seeds improves performance after seed storage. J. Hort. Sci. 71:287-295.

Sari, A.O., M.R. Morales, and J.E. Simon. 2001. Ethephon can overcome seed dormancy and improve seed germination in purple coneflower species Echinacea angustifolia and E. pallida. HortTechnology 11:202-205.

Smith-Jochum, C.C. and M.L. Albrecht. 1987. Field establishment of three Echinacea species for commercial production. Acta Hort. 208:115-120.

Sorenson, J.T. and D.J. Holden. 1974. Germination of prairie ford seed. J. Range Mgt. 27:123-126.

Wartidiningsih, N. and R.L. Geneve. 1994. Seed source and quality influence germination in purple coneflower [Echinacea purpurea (L.) Moench.]. HortScience 29:1443-1444.

Wartidiningsih, N., R.L. Geneve, and S.T. Kester. 1994. Osmotic priming and chilling stratification improves seed germination of purple coneflower. HortScience 29:1445-1448. 